\title{
PERTUMBUHAN DAN PRODUKSI KEDELAI AKIBAT INOKULASI BAKTERI RHIZOBIUM DAN PENAMBAHAN HARA AIR LAUT
}

\author{
Eny Fuskhah dan Adriani Darmawati \\ Fakultas Peternakan dan Pertanian Universitas Diponegoro Semarang \\ Email : eny_fuskhah@yahoo.com
}

\begin{abstract}
ABSTRAK
Penelitian bertujuan memanfaatkan air laut yang melimpah sebagai sumber hara bagi tanaman khususnya kedelai sehingga menghemat penggunaan pupuk buatan serta dikombinasikan dengan pemanfaatan gulma air eceng gondok sebagai mulsa, dan aplikasi bakteri Rhizobium. Penelitian dilaksanakan di rumah kaca Laboratorium Ekologi dan Produksi Tanaman Fakultas Peternakan danPertanian Universitas Diponegoro Semarang. Sampel air laut diambil dari Pantai Marina Semarang. Benih kedelai yang digunakan adalah benih lokal Grobogan. Rancangan percobaan adalah Rancangan Acak Lengkap pola Faktorial 4 x 2 dengan 4 ulangan. Faktor pertama adalah kombinasi air laut dan mulsa eceng gondok meliputi : Lo = tanpa air laut (air tawar) dan tanpa mulsa eceng gondok (kontrol), L1 = Kombinasi level air laut $1 \mathrm{mmhos} / \mathrm{cm}$ dan 8 ton/ha mulsa eceng gondok, L2 = Kombinasi level air laut $2 \mathrm{mmhos} / \mathrm{cm}$ dan 8 ton/ha mulsa eceng gondok, L3 = Kombinasi level air laut $3 \mathrm{mmhos} / \mathrm{cm}$ dan 8 ton/ha mulsa eceng gondok. Faktor kedua adalah perlakuan inokulasi bakteri Rhizobium meliputi : R1 = tanpa inokulasi bakteri Rhizobium, R2 = dengan inokulasi bakteri Rhizobium. Parameter yang diamati meliputi panjang tanaman, jumlah daun, produksi berat segar tajuk, dan produksi bahan kering tajuk. Data yang diperoleh dianalisis ragam dan untuk mengetahui perbedaan antar perlakuan dilanjutkan dengan Uji Wilayah Berganda Duncan (Steel dan Torrie, 1995). Hasil penelitian menunjukkan tidak ada pengaruh interaksi antara level salinitas air laut dengan inokulasi bakteri rhizobium terhadap panjang tanaman, jumlah daun, berat segar tajuk, dan produksi bahan kering tajuk. Pemberian hara air laut dan inokulasi bakteri rhizobium cenderung meningkatkan pertumbuhan dan produksi tanaman kedelai.
\end{abstract}

Kata kunci : kedelai, hara air laut, rhizobium, pertumbuhan, produksi

\begin{abstract}
The research aim is to use sea water as nutrient source of plant especially soybean, so it reduces amount of anorganic fertilizer usage. The research held in green house of Ecology and Plant Production Laboratory of Animal Husbandry and Agriculture Faculty, Diponegoro University Semarang. Sea water as sample was taken from Semarang Marina Beach. Soybean which choosen is local bean of Grobogan. The design arranged was completely randomized design with factorial design $4 \times 2$ in 4 replications. First factor was sea water salinity level, Lo = without sea water and without mulch, L1 = sea water EC $1 \mathrm{mmhos} / \mathrm{cm}$ and water hyacinth mulch of 8 tons/ha, L2 = sea water EC $2 \mathrm{mmhos} / \mathrm{cm}$ and water hyacinth mulch of 8 tons/ha, L3 = sea water EC $3 \mathrm{mmhos} / \mathrm{cm}$ and water hyacinth mulch of 8 tons/ha. The second factor was Rhizobium inoculation, R1 = without rhizobium inoculation, and $\mathrm{R} 2$ = with Rhizobium inoculation. The parameters were length plant, number of leaves, fresh weight production of shoot and dry matter production. Based on variant analysis, showed no influenced between sea water salinity level and rhizobium inoculation againt to length plant, number of leaves, fresh weight production of shoot and dry matter production. Sea water and rhizobium inoculation tended to increase growth and production of soybean.
\end{abstract}

Key words : soybean, nutrient of sea water, rhizobium, growth, production.

\section{PENDAHULUAN}

Tanaman kedelai (Glycine max L) merupakan salah satu komoditas pangan bergizi tinggi sebagai sumber protein nabati dan rendah kolesterol. Kedelai juga merupakan komoditas pangan yang penting setelah padi dan jagung. Konsumsi kedelai dalam bentuk segar maupun dalam bentuk olahan dapat meningkatkan gizi masyarakat. Di Indonesia, kedelai banyak diolah untuk berbagai macam bahan pangan, seperti : tauge, susu kedelai, tahu, kembang tahu, kecap, oncom, tauco, tempe, dan tepung kedelai. Selain itu, juga banyak dimanfaatkan sebagai bahan pakan ternak. 
Tanaman kedelai merupakan tanaman leguminosa mempunyai kemampuan bersimbiosis secara mutualistik dengan bakteri Rhizobium sp yang tumbuh di daerah perakarannya. Adanya bakteri ini menyebabkan terbentuknya nodul/bintil akar yang mampu memfiksasi nitrogen bebas dari udara sehingga dapat mensuplai kebutuhan tanaman akan unsur N. Kebutuhan nitrogen tanaman oleh fiksasi nitrogen terjadi tidak pada awal fase vegetatif dan akhir masa reproduktif, tetapi terjadi setelah pembentukan bintil yang terjadi karena kolonisasi rhizosfer dan infeksi rhizobia pada akar leguminosa (Beck et al., 1991). Hasil simbiosis ini diharapkan mampu meningkatkan produksi hijauan tanaman. Penelitian Fuskhah et al. (1997) menunjukkan bahwa penggunaan inokulum Rhizobium dari $20-60 \mathrm{~g} / \mathrm{kg}$ benih dikombinasikan dengan pemupukan fosfor dapat meningkatkan produksi bahan kering hijauan Centrosema pubescens Benth. Kemampuan untuk memfiksasi nitrogen dapat mengurangi biaya pembelian pupuk $\mathrm{N}$ buatan, sehingga aplikasi inokulasi Rhizobium pada tanaman leguminosa menjadi sangat penting untuk memacu fiksasi nitrogen.

Di sisi lain, air laut yang begitu melimpah di Indonesia ternyata mengandung banyak ion, termasuk ion-ion yang dibutuhkan tanaman. Kandungan unsurunsur yang dibutuhkan tanaman seperti magnesium $(\mathrm{Mg})$, calcium (Ca), dan kalium (K) yang ada di air laut cukup tinggi. Hal ini menunjukkan bahwa air laut dapat menjadi sumber alternatif hara atau nutrien bagi tanaman.

Rata-rata konsentrasi garam terlarut di air laut sekitar 3,5\%, tergantung pada lokasi dan laju evaporasi (Brown et al., 1989). Diantara garam-garam tersebut, konsentrasi natrium $(\mathrm{Na})$ dan chloride $(\mathrm{Cl})$ adalah dominan dan terdapat dalam jumlah besar sehingga mengakibatkan tingginya salinitas (Pickard dan Emery, 1990). Oleh karena itu, dalam penggunaannya, air laut perlu diencerkan terlebih dahulu untuk mengurangi salinitasnya sampai ambang yang tidak membahayakan tanaman.

Air laut pada prakteknya banyak digunakan untuk mengairi tanaman yang toleran terhadap salinitas (halophyte) pada daerah-daerah dekat pantai. Turi (Sesbania grandiflora) menurut hasil penelitian Fuskhah et al. (2007) tahan terhadap tingkat $\mathrm{NaCl}$ tinggi, sampai $4000 \mathrm{ppm} \mathrm{NaCl}$ atau setara dengan EC (electrical conductivity) 7,5 mmhos/cm masih menunjukkan peningkatan produksi. Hal ini diduga turi termasuk tanaman halophyta yang tahan terhadap tingkat salinitas tinggi.

Penelitian bertujuan memanfaatkan air laut yang melimpah sebagai sumber hara bagi tanaman kedelai sehingga menghemat penggunaan pupuk buatan serta dikombinasikan dengan pemanfaatan gulma air eceng gondok sebagai mulsa, dan aplikasi bakteri Rhizobium.

Hipotesis penelitian adalah ada interaksi antara hara air laut dan eceng gondok sebagai mulsa juga aplikasi bakteri Rhizobium untuk meningkatkan pertumbuhan dan produksi jerami kedelai.

\section{METODE PENELITIAN}

Penelitian dilaksanakan di rumah kaca Fakultas Peternakan dan Pertanian Universitas Diponegoro Semarang.

Materi : air laut, eceng gondok, isolat bakteri Rhizobium, benih kedelai, EC meter, pot, oven, mistar, pupuk N, P, dan K.

Metode : Sebanyak 32 pot diisi tanah dan disterilkan. Benih kedelai disiapkan. Pupuk dasar yang

digunakan adalah pupuk N, P, dan K masingmasing dengan dosis $100 \mathrm{~kg} \mathrm{~N} / \mathrm{ha}, 150 \mathrm{~kg}$ P2O5/ ha, dan $100 \mathrm{~kg} \mathrm{K2O} / \mathrm{ha}$. Air laut digunakan untuk penyiraman dengan dosis pengenceran sesuai perlakuan.

Rancangan percobaan yang digunakan adalah Rancangan Acak Lengkap Pola Faktorial 4 x 2 dengan 4 ulangan.

Faktor pertama adalah kombinasi air laut dan mulsa eceng gondok yaitu :

Lo = tanpa air laut (air tawar) dan tanpa mulsa eceng gondok (kontrol)

$\mathrm{L} 1=$ Kombinasi level air laut $1 \mathrm{mmhos} / \mathrm{cm}$ dan 8 ton/ha mulsa eceng gondok

L2 = Kombinasi level air laut $2 \mathrm{mmhos} / \mathrm{cm}$ dan 8 ton/ha mulsa eceng gondok

$\mathrm{L} 3=$ Kombinasi level air laut $3 \mathrm{mmhos} / \mathrm{cm}$ dan 8 ton/ha mulsa eceng gondok

Faktor kedua adalah perlakuan inokulasi bakteri Rhizobium yaitu :

$\mathrm{R} 1$ = tanpa inokulasi bakteri Rhizobium

R2 = dengan inokulasi bakteri Rhizobium

Parameter yang diamati meliputi panjang tanaman, jumlah daun, produksi berat segar dan bahan kering jerami. Data yang diperoleh dianalisis ragam dan untuk mengetahui perbedaan antar perlakuan dilanjutkan dengan Uji Wilayah Berganda Duncan (Steel dan Torrie, 1995).

\section{HASIL DAN PEMBAHASAN}

\section{Pertumbuhan Kedelai}

Hasil analisis ragam menunjukkan bahwa tidak ada interaksi antara perlakuan penambahan air laut dengan inokulasi bakteri rhizobium terhadap parameter pertumbuhan yaitu panjang tanaman, dan jumlah daun (Tabel 1 dan 2). 
Tabel 1. Rerata Panjang Tanaman Kedelai pada Berbagai Level Salinitas Air Laut dan Inokulasi Bakteri Rhizobium

\begin{tabular}{|c|c|c|c|}
\hline \multirow{3}{*}{$\begin{array}{l}\text { Level Salinitas } \\
\text { Air Laut }\end{array}$} & \multicolumn{2}{|c|}{ Inokulasi Rhizobium } & \multirow{3}{*}{ Rerata } \\
\hline & R1 (tanpa) & R2 (dengan Inokulasi & \\
\hline & \multicolumn{2}{|c|}{$\ldots$} & \\
\hline LO (tanpa air laut) & 112,50 & 101,25 & 106,88 \\
\hline L1 (EC 1 mmhos/cm) & 120,13 & 119,38 & 119,75 \\
\hline L2 (EC 2 mmhos/cm) & 114,63 & 124,50 & 119,56 \\
\hline L3 (EC 3 mmhos/cm) & 112,38 & 110,25 & 111,31 \\
\hline Rerata & 114,91 & 113,84 & \\
\hline
\end{tabular}

Tabel 2. Rerata Jumlah Daun Tanaman Kedelai pada Berbagai Level Salinitas Air Laut dan Inokulasi Bakteri Rhizobium

\begin{tabular}{|c|c|c|c|}
\hline \multirow{3}{*}{$\begin{array}{l}\text { Level Salinitas } \\
\text { Air Laut }\end{array}$} & \multicolumn{2}{|c|}{ Inokulasi Rhizobium } & \multirow{3}{*}{ Rerata } \\
\hline & R1 (tanpa) & R2 (dengan Inokulasi & \\
\hline & \multicolumn{2}{|c|}{.............(helai petiole)................ } & \\
\hline LO (tanpa air laut) & 9,13 & 9,50 & 9,31 \\
\hline L1 (EC 1 mmhos/cm) & 9,63 & 10,63 & 10,13 \\
\hline L2 (EC 2 mmhos/cm) & 10,63 & 10,50 & 10,56 \\
\hline L3 (EC $3 \mathrm{mmhos} / \mathrm{cm}$ ) & 11,25 & 13,75 & 12,50 \\
\hline Rerata & 10,16 & 11,09 & \\
\hline
\end{tabular}

Tabel 1 dan 2 menunjukkan bahwa perlakuan penambahan air laut cenderung meningkatkan pertumbuhan tanaman kedelai walaupun tidak signifikan. Air laut ternyata mengandung banyak ion. Kandungan unsur-unsur yang dibutuhkan tanaman seperti magnesium (Mg), calcium (Ca), dan kalium (K) yang ada di air laut cukup tinggi (Yufdy dan Jumberi, 2011). Dengan penambahan air laut berarti menambah pula hara yang diberikan tanaman. Namun air laut yang diberikan harus diencerkan terlebih dahulu karena kandungan $\mathrm{Na}$ dan $\mathrm{Cl}$ yang sangat tinggi. Kandungan $\mathrm{Na}$ dan $\mathrm{Cl}$ yang terlalu tinggi mengganggu pertumbuhan tanaman. Namun natrium pada level tertentu, dapat dimanfaatkan sebagai unsur hara pada jenis-jenis tanaman tertentu yang membutuhkannya baik sebagai unsur tambahan maupun sebagai pengganti sebagian dari kebutuhan unsur K (Yufdy dan Jumberi, 2011). Tingkat salinitas media tanam dengan electrical conductivity (EC) o -2 mmhos/ cm umumnya belum membahayakan bagi tanaman (Tan, 1991). Tingginya kandungan hara yang ada pada air laut menunjukkan bahwa air laut dapat menjadi alternatif sumber hara atau nutrien bagi tanaman.

\section{Produksi Kedelai}

Hasil analisis ragam menunjukkan bahwa tidak ada interaksi antara perlakuan penambahan air laut dengan inokulasi bakteri rhizobium terhadap parameter produksi yaitu produksi bahan segar dan produksi bahan kering jerami kedelai (Tabel 3 dan 4).

Tabel 3 dan 4 menunjukkan bahwa penambahan hara air laut dan inokulasi bakteri rhizobium secara sendiri cenderung meningkatkan produksi jerami kedelai dibandingkan dengan tanpa penambahan air laut dan inokulasi rhizobium. Tanaman kedelai
Tabel 3. Rerata Produksi Berat Segar Jerami Kedelai pada Berbagai Level Salinitas Air Laut dan Inokulasi Bakteri Rhizobium

\begin{tabular}{|c|c|c|c|}
\hline \multirow{3}{*}{$\begin{array}{l}\text { Level Salinitas } \\
\text { Air Laut }\end{array}$} & \multicolumn{2}{|c|}{ Inokulasi Rhizobium } & \multirow{3}{*}{ Rerata } \\
\hline & $\mathrm{R} 1$ (tanpa) & R2 (dengan Inokulasi & \\
\hline & \multicolumn{2}{|c|}{.............(g/pot)............... } & \\
\hline LO (tanpa air laut) & 24,25 & 30,13 & 27,19 \\
\hline L1 (EC 1 mmhos/cm) & 27,00 & 27,50 & 27,25 \\
\hline L2 (EC 2 mmhos/cm) & 30,13 & 30,50 & 30,31 \\
\hline L3 (EC 3 mmhos/cm) & 25,88 & 33,25 & 29,56 \\
\hline Rerata & 26,81 & 30,34 & \\
\hline
\end{tabular}

Tabel 4. Rerata Produksi Bahan Kering Jerami Kedelai pada Berbagai Level Salinitas Air Laut dan Inokulasi Bakteri Rhizobium

\begin{tabular}{lccc}
\hline \multirow{2}{*}{\begin{tabular}{c} 
Level Salinitas Air \\
\cline { 2 - 2 }
\end{tabular}} & \multicolumn{2}{c}{ Inokulasi Rhizobium } & \multirow{2}{*}{ Rerata } \\
\cline { 2 - 3 } & R1 (tanpa) & R2 (dengan Inokulasi & \\
\hline L0 (tanpa air laut) & $7,72 \ldots \ldots . .(\mathrm{g} /$ pot) $\ldots \ldots \ldots \ldots . . .$. & 8,05 \\
L1 (EC 1 mmhos/cm) & 8,97 & 8,38 & 8,23 \\
L2 (EC 2 mmhos/cm) & 9,88 & 7,50 & 9,27 \\
L3 (EC 3 mmhos/cm) & 7,38 & 8,65 & 8,36 \\
Rerata & 8,49 & 9,35 & \\
\hline
\end{tabular}

merupakan tanaman leguminosa mempunyai kemampuan bersimbiosis secara mutualistik dengan bakteri Rhizobium sp yang tumbuh di daerah perakarannya. Adanya bakteri ini menyebabkan terbentuknya nodul/bintil akar yang mampu memfiksasi nitrogen bebas dari udara sehingga dapat mensuplai kebutuhan tanaman akan unsur N. Akar tanaman menyediakan hara dan karbohidrat untuk energi bakterinya dan bakteri menyediakan senyawa nitrogen yang ditambat (Handayanto dan Hairiah, 2007). Kebutuhan nitrogen tanaman oleh fiksasi nitrogen terjadi tidak pada awal fase vegetatif dan akhir masa reproduktif, tetapi terjadi setelah pembentukan bintil yang terjadi karena kolonisasi rhizosfer dan infeksi rhizobia pada akar leguminosa (Beck et al., 1991). Hasil simbiosis ini diharapkan mampu meningkatkan produksi hijauan tanaman.

\section{KESIMPULAN}

Hasil penelitian menunjukkan tidak ada pengaruh interaksi antara level salinitas air laut dengan inokulasi bakteri rhizobium terhadap panjang tanaman, jumlah daun, berat segar tajuk, dan produksi bahan kering tajuk. Pemberian hara air laut dan inokulasi bakteri rhizobium cenderung meningkatkan pertumbuhan dan produksi tanaman kedelai.

\section{DAFTAR PUSTAKA}

Beck, D.P., J.Wery, M.C. Saxena and A.Ayadi. 1991. Dinitrogen fixation and nitrogen balance in cool season food legumes. Agronomy Journal 83 : 334-341.

Brown, J., A. Colling, D. Park, J. Phillips, D. Rothery 
and J. Wright. 1989. Ocean Circulation. New York. Pergamon Press.

Fuskhah, E, E.D. Purbayanti, F. Kusmiyati dan R.T. Mulatsih. 1997. Efek inokulasi Rhizobium Sp dan pemberian fosfor terhadap derajat katalisis enzim nitrogenase nodul akar Centrosema pubescens Benth. Majalah Penelitian. Lembaga Penelitian Universitas Diponegoro. IX(34): 19-25

Fuskhah, E., R. D. Soetrisno, S. Anwar dan F. Kusmiyati. 2007. Rekayasa Ketahanan Bakteri Rhizobium dan Tanaman Leguminosa Pakan terhadap Cekaman Salinitas di Daerah Salin Pantai Seminar Nasional IV - HITPI. "Strategi Pengembangan Hijauan Pakan Lokal Berkualitas Untuk Peningkatan Mutu Ternak" Purwokerto 18 - 20 Oktober 2015 .ISBN. 53 Utara Jawa Tengah. Laporan Penelitian Hibah
Bersaing, Direktorat Jenderal Pendidikan Tinggi, Departemen Pendidikan Nasional.

Handayanto, E. dan K. Hairiah. 2007. Biologi Tanah Landasan Pengelolaan Tanah Sehat. Pustaka Adipura. Yogyakarta.

Pickard, G.L. and K. O. Emery, 1990. Descriptive Physical Oceanography, Pergamon Press.

Steel, R.G.D. dan J.H. Torrie.1995. Prinsip dan Prosedur Statistika Suatu Pendekatan Biometrik. Alih Bahasa : Bambang Sumantri. P.T. Gramedia Pustaka Utama. Jakarta.

Tan, K. H. 1991. Dasar-Dasar Kimia Tanah. Gadjah Mada University Press, Yogyakarta (Diterjemahkan D. H. Goenadi).

Yufdy, M.P. dan A. Jumberi. 2011. Pemanfaatan Hara Air Laut untuk memenuhi KebutuhanTanaman. Http://www.dpi.nsw.gov.au. Access date 7 Maret 2011 